\title{
Catching-up or Leapfrogging? The effects of competition on innovation and growth
}

\author{
David Encaoua*and David Ulph ${ }^{\dagger}$
}

November $2004^{\ddagger}$

\begin{abstract}
The main objective of this paper is to analyze the links between product market competition, innovation and growth. In a step-by step innovation model we explicitly introduce the distinction between knowledge and technology information flows. Patents protect their holders from being imitated or copied but do not protect them against the possibility that less efficient rivals master the disclosed knowledge, allowing them to start a new race from the cutting edge of the technology rather than from their own technology. We show that this distinction has important consequences. The knowledge information flow increases the positive effect of competition on innovation and growth while the technology information flow has a negative effect. We also decompose the overall effect of competition as the sum of two opposite effects: a negative level effect (competition lowers individual profits in industries where all firms are symmetric) and a positive spread effect (the spread of profits between asymmetric firms increases with the intensity of competition). These effects encompass the selection effect of competition. Finally we give support to the idea that a higher short run competition does not favor the long run competition.
\end{abstract}

*EUREQua, Université Paris I, Panthéon-Sorbonne

${ }^{\dagger}$ ELSE, University College London

${ }^{\ddagger}$ A preceding version of this paper has benefited from helpful comments by Philippe Aghion, Jean-Pascal Benassy, Claude Crampes, Saul Lach and Mark Machina. The authors gratefully acknowledge the help of Emmanuel Duguet for the numerical simulations. 


\section{Introduction}

The link between product market competition, innovation and growth has been at the heart of much of the economic theory of innovation, going back to the classic works of Schumpeter (1934), Arrow (1962) and Dasgupta and Stiglitz (1980). It has been also one of the much debated questions in endogenous growth theory. Until very recently, the consensus emerging from the endogenous growth literature was that increasing product market competition is bad for innovation and growth - see for example Aghion and Howitt (1992, 1996), Grossman and Helpman (1991), Caballero and Jaffe (1993). The endogenous growth models of the first generation from which this result was derived were based on the Schumpeterian representation of growth taking place through a process of creative destruction. This means that innovation takes the form of what can be called strong leapfrogging in which not only the innovating firm has to leapfrog the current insider to become a leader but also the innovator is necessarily an outsider. Therefore, each industry is characterized by a persistent monopoly - with the identity of the monopolist changing overtime. The conclusion that emerges from these models is a simple consequence of the Arrow's replacement effect. If the incumbent has no R\&D advantage, it has a weaker incentive to innovate than outsiders, since the incumbent captures only the incremental rent associated to the innovation while outsiders earn no rents if they fail to innovate and become monopolies if they do innovate. Then, the monopoly rents of a successful innovator decrease when environment becomes more competitive and the incentive to invest by an outsider also clearly decreases. Note that, in these models, no competition occurs except at the R\&D activity level and, it is impossible to derive from them a direct relationship between the degree of rivalry in the product market and the incentive to innovate. Moreover, the Schumpeterian framework of these models does not correspond exactly to what we generally observe: innovation occurs frequently within industries that contain more than one firm; it also occurs within existing firms that are already earning rents and the competitive pressure in the product market is not absent from the innovative process. In contrast to what suggest the results of these growth models, the merits of competition are often invoked to justify the conventional wisdom on which much public policy relies: a higher competitive pressure should increase the incentive to innovate, inasmuch as firms create new products and processes in order to escape - albeit temporarily - from the pressures of competition. 
A second generation of models, driven from the literature on patent races, has enriched our understanding of the links between competition and innovation $^{1}$. Budd et al. (1993) analyze a situation of successive innovations in which firms anticipate the long run effects of their R\&D behavior. Their framework allows an assessment of the dynamics of competition and an identification of the factors affecting the industry evolution characterized by either increased or decreased asymmetries between firms overtime. A recent paper by Boone (2001) offers a very general framework to analyze the link between market rivalry and the incentive to innovate. It shows that in a situation involving asymmetric firms, the identity of the winner of a process innovation depends on three factors: the ex-ante cost structure distribution, the level of the technological gap induced by the process innovation and the degree of rivalry in the product market. There is a change in the identity of the winner as the degree of rivalry in the product market increases and the relation between the rivalry in the market and the R\&D incentives is nonmonotonic. When market rivalry is below some threshold, a laggard firm has a higher incentive to invest than the firm ahead: it leapfrogs the leader. But when the degree of competition is above another threshold, the inverse result prevails: the firm ahead has a higher incentive to innovate and to increase its dominance. In other words, when the intensity of competition is sufficiently high, the replacement effect is outweighed by the efficiency effect and the leadership persists. These interesting results have been obtained for a broad class of indexes measuring the degree of rivalry in the industry. These indexes satisfy axioms that focus on the selection effect of competition, according to which more competition shifts resources from inefficient firms to an efficient one. ${ }^{2}$ The main limitation of Boone's model is that the analysis is restrained to the case of a single innovation. The more realistic but more complex case of a sequence of successive innovations has been the main topic in Budd et al. (1993). By incorporating some specificities of the dynamics of innovation included in Budd et al., Aghion et al. (1997) propose a second generation endogenous growth model in which the strong leapfrogging assumption is replaced by a process of step-by-step innovation. A technological laggard

\footnotetext{
${ }^{1}$ Among influential papers on the patent race literature devoted to the evolution of an industry in a dynamic competitive setting, see Harris and Vickers (1985, 1987), Vickers (1986), Beath, Katsoulacos and Ulph (1987), Reinganum (1981a,b,c, 1982, 1983, 1985), Bessen and Maskin (2002). See also the survey by Reinganum (1989).

${ }^{2}$ See Boone (2000) for an analysis of the intensity of competition effect for a product innovation.
} 
has to catch-up the leading edge technology before racing for technological leadership in the future. In this setting, the link between competition and innovation depends on both the current cost structure of an industry and the intensity of competition in the productmarket. In a neck-and-neck type of industry where competitors have access to the same technology, a more intense competition stimulates R\&D investment. Each firm is motivated to innovate in order to escape from competition that prevails between head-byhead rivals. However, in unleveled industries where a firm is one step ahead, more competition decreases the short run incentive to invest by the laggard firm since the profits that it expects from catching-up the firm ahead decrease with the intensity of competition. Moreover, there exists an indirect effect of the competitive pressure: a higher competition intensity lowers the proportion of neck-and-neck industries in the economy as each firm tries to escape from this type of industries. The overall characterization of both the $\mathrm{R} \& \mathrm{D}$ efforts and the proportion of leveled industries in the long run allows an assessment of the effect of competitive rivalry on innovation and growth. Two extensions have been made in Aghion et al. (2001): first, the size of technological gaps between firms and across industries has been allowed to incorporate more than one step; second, the degree of product market competition has been measured by the elasticity of substitution of the products sold by the duopolists in each industry. Their results confirm the results by Boone (2001): the overall effect of product market competition on innovation and growth has an inverse $\mathrm{U}$ form. It is monotonically increasing and positive when the degree of rivalry is below some threshold and it is decreasing when the degree of rivalry is above the threshold.

In this paper we extend Aghion et al. (1997) in another direction. We introduce the distinction between knowledge information flows and technology information flows. Even if knowledge and technology are made proprietary under an intellectual property right, we claim that the diffusion of knowledge enlarges the possible dynamics of an industry. Suppose that an innovation is patented and that the patent discloses information. In a step-by-step process, the next innovation depends on the extent to which others can master the disclosed knowledge information behind the invention. The patent protects its holder from having its technology copied or imitated by others but it does not protect against the possibility that a competitor successfully masters the disclosed knowledge, allowing it to start a new race from the cutting edge in order to reach the next improved technology. In other words, in a step-by-step innovation framework, it is possible to leapfrog the patent 
holder's technology without having to catching-up with it before. One of the main justifications of the patent system over the trade secrecy is that a patent favours the diffusion of knowledge from the compulsory disclosure requirement. This aspect is emphasized in Gallini (2002, p.139-140): "Patents present a bargain between society and the inventor in which society benefits from disclosure of the invention and the inventor receives exclusive rights over the technology for 20 years... The disclosure requirement under the American Inventors Protection Act of 1999-which requires that patent applications be open for public inspection 18 months after the filing date- may improve the flow of information from patent applications". ${ }^{3}$

The consequence is that, in a step-by-step innovation framework, the firms that are currently in different positions with regard to their technological efficiency levels may nevertheless start a new race from the same cutting edge technology. Our framework gives a full recognition to this possibility. In these conditions, catching-up and leapfrogging appear as special cases of a more general situation where the rate of knowledge diffusion becomes central. The knowledge diffusion rate is affected either by licensing practices or by individual learning practices allowing a competitor to understand and master the knowledge disclosed in the patent. In this paper we represent the knowledge diffusion rate as the conditional probability that a laggard firm improves the cutting edge technology rather than its own technology when it succeeds in innovating. This extension allows a deeper investigation of the effects of an increase in the intensity of rivalry on innovation and growth.

As in Aghion et al. (1997), each industry in our model has just two firms and we also assume that the maximum gap between the firms is always of one step. This means that patents only protect the latest technology: when a firm moves onto a new technological frontier, the patent lapses on the previous technology. We also assume that any firm that acquires a technology through the lapse of a patent also acquires the knowledge associated with the technology.

The implications of these assumptions are clear. Consider for instance the situation of an industry in which two asymmetric firms compete. One

\footnotetext{
${ }^{3}$ The information becomes publicly available before the patent is granted. The same delay of 18 months prevails between the filing date and the publication of the disclosed information for patents that apply to the European Patent Office. Note that, at an international level, the obligation to publish applications before grant has also been introduced as a minimum requirement in the agreement on Trade Related Aspects of Intellectual Property Rights (TRIPS).
} 
firm is on the leading-edge technological frontier and has the knowledge associated with that frontier. The other firm is one step behind and has both the technology and the knowledge associated with its own technological frontier. Under the patent system, the follower is not allowed to use the leading technology by simply copying it. Both firms can undertake R\&D in order to move forward. Therefore two possible outcomes may arise: (i) The leader succeeds in innovating. In this case the leader will move one step ahead and acquire both the knowledge and the technology associated with the new technological frontier. However given our assumption that patents protect only the latest technological frontier, the follower is able to acquire the technology at the current frontier and, since it hasn't just copied the technology, it also acquires the knowledge at the current frontier. Thus the industry stays in a leader-follower situation and the leader's gap remains equal to one step. (ii) The follower succeeds in innovating. In this case we assume that there is a probability $\theta$ that, in the course of doing its $\mathrm{R} \& \mathrm{D}$, the follower will master the knowledge at the current frontier, and so, if it succeeds in innovating, will actually acquire both the knowledge and the technology associated with the new frontier. Thus the follower will leapfrog the current leader with probability $\theta$. However, with probability $1-\theta$, the follower will not master the ideas at the current frontier, and so its one step of progress will just take it onto the existing frontier alongside the leader, leading to a situation of neck-by-neck competition.

Thus our model allows both leapfrogging and catch-up. Leapfrogging may be either strong or weak, depending on the technological gap induced by a one step ahead move. A strong leapfrogging occurs when the innovator acquires a monopoly on the product market because the technological gap is high. A weak leapfrogging is related to the situation where the innovator acquires just a temporary leadership that can be contested by the laggard firm during the subsequent race. While the endogenous growth models of the first generation focused on the strong leapfrogging assumption and those of the second generation (step-by-step) on the weak leapfrogging one, our model encompasses both assumptions as special cases of a more general assumption. The dynamics of transition are more complex than in strong leapfrogging and step-by-step innovation models, since an industry can move from a leaderfollower type to a neck-and-neck type or to another leader-follower situation with the respective roles of the leader and follower being reversed.

Besides the knowledge flows of information, there exist also technology flows of information, also called technology spillovers, according to which a 
technology can be imitated by others, insofar as a patent does not offer to its holder a perfect protection ${ }^{4}$. We capture the possibility of imperfect patent protection by assuming that in a leader-follower situation there is a probability $\delta, 0 \leq \delta \leq 1$, that the follower can acquire the current frontier technology - but not the underlying knowledge - simply by copying or imitating it.

There are therefore two independent flows of information in this model: one about underlying knowledge that is represented by the parameter $\theta$, the second about technology that is represented by the parameter $\delta$. These flows of information are logically and statistically independent. For instance $\theta$ could be high in industries where there exists a well developed scientific community and firms employ well trained scientists capable of mastering the latest advances, while $\delta$ could be low because patents are very effective in preventing firms from simply copying other firms' technologies. Conversely, in some other industries, $\theta$ could be very low because the nature of knowledge is such that it is impossible to master an idea without having discovered it oneself, while $\delta$ could be high because it is relatively easy to simply copy technologies. Thus, $\delta$ corresponds to the usual spillover parameter that has been much analyzed in the literature on innovation. Since the distinction between technology and knowledge is not frequently made, there has been less attention devoted to the role of $\theta$. As we will show, the distinction between these two knowledge flows is crucial insofar as their impact on innovation is dramatically different: The parameter $\theta$ controls the basic dynamics of the innovation process whereas $\delta$ just affects the profits available in leaderfollower situations.

We turn now to the measure of the intensity of competition in the product market used in this paper. There exist different possible measures and Boone $(2001 \mathrm{a}, \mathrm{b})$ suggests a useful common requirement. A parameter $\rho$ will serve as an indicator of competition as long as it satisfies a short run reallocation effect property stating that "competition reallocates profits from inefficient to more efficient firms: A rise in competition raises the profits of a firm relative to the profits of a less efficient firm and reduces the profits of the least efficient firm in the market". The reallocation effect implies the selection effect of the competitive process invoked in Budd et al (1993) and Vickers (1995) in situations where firms' costs differ. We use in this paper

\footnotetext{
${ }^{4} \mathrm{~A}$ recent paper by Anton and Yao (2004) analyzes the consequences of an imperfect patent protection when the innovator has a private information on the cost reduction level that its innovation allows, the cost reduction being signalled by the amount of disclosed information that the innovator chooses when adopting the decision to apply for a patent.
} 
the conjectural variation parameter $\rho$ as an index of the intensity of competition. We analyze below the selection effect properties of this measure of the intensity of competition.

We use this general framework to investigate the following questions:

(i) How innovation and growth are affected by the intensity of competition represented by the conjectural variation parameter $\rho$ ?

(ii) How innovation and growth are affected by the two types of information flows related to knowledge and technology and represented respectively by the parameters $\theta$ and $\delta$ ?

The model also enables us to address a third issue. Does innovation result in industries which are more frequently of the leader-follower type or more frequently of the neck-and-neck type? We ask thus how the frequency with which the industry is in the neck-and-neck situation is affected by firms having to work in a more competitive environment. Put somewhat differently, the third question is:

iii) How the short term competition affects the long term competition?

The paper is organized as follows. The basic set-up is described in section 2. The determination of the value functions, the distribution of industries according to their type and, the rate of growth of the economy are obtained in section 3. In Section 4 a quadratic R\&D cost function is specified and the solution of the model is determined as the unique solution of a system of equations. In section 5 , we derive the properties of the short run incentives to innovate given by the incremental profits and we introduce the distinction between the level effect and the spread effects of competition. The main results concerning the impact of the degree of rivalry $\rho$ on innovation and growth are presented in section 6 . In Section 7 , we examine the impact of the two knowledge flows $\theta$ and $\delta$ on innovation and growth. The concluding remarks appear in section 8 .

\section{The basic set-up}

\subsection{The consumption side}

The assumptions with regard to the consumption side are made as simple as possible. In particular, we choose a utility function that allows a unitelasticity demand curve in each industry, such that current market profits depend only on the relative firm's levels of efficiency and not on the absolute 
levels. We suppose that there exists a continuum of final goods in the economy. Each good is produced in a specific industry indexed by $i \in[0,1]$. Consumption of output from industry $i$ at time $t$ is denoted by $c_{i}(t)$. Time is continuous. We suppose that the representative consumer is infinitely lived and has a separable intertemporal utility function given by:

$$
U=\int_{0}^{\infty} \ln C(t) e^{-\sigma t} d t
$$

In this expression, $C(t)$ represents an index of overall consumption at date $t$ defined by:

$$
\ln C(t)=\int_{0}^{1} \ln c_{i}(t) d i
$$

and $\sigma \geqslant 0$ is the rate of time preference (discount rate).

We suppose that financial markets are perfect and characterized by an instantaneous interest rate $r_{t}$. Denote by $E(t)$ the instantaneous global expenditure at date $t: E(t) \equiv P(t) C(t)$ where $P(t)$ is the general price index at date $t$ defined by: $\ln P(t)=\int_{0}^{1} \ln p_{i}(t) d i$ and $p_{i}(t)$ is the price in industry $i$ at date $t$. Since the intertemporal rate of substitution in (1) is constant and equal to unity, the maximization of $U$ under an intertemporal budget constraint leads to the standard Ramsey equation ${ }^{5}$ :

$$
\frac{\dot{E}(t)}{E(t)}=\sigma-r_{t}
$$

We choose the following normalization rule:

$$
E(t) \equiv P(t) C(t)=1 \forall t \in[0, \infty[
$$

According to (3) and (4), the interest rate $r_{t}$ is thus equal to the discount rate $\sigma$ :

$$
r_{t}=\sigma \forall t \in[0, \infty[
$$

We will denote $r$ the constant rate of interest.

According to (2), each final good has the same weight in the instantaneous utility function. Thus the normalization rule leads also to a uniform spending in each industry:

\footnotetext{
${ }^{5}$ See Grossman and Helpman (1997), page 48.
} 


$$
p_{i}(t) c_{i}(t)=1 \forall t \in[0, \infty[, \forall i \in[0,1]
$$

\subsection{The productive side}

In this section we assume that patent protection is perfect and consequently that there is no imitation of a protected technology, i.e. we assume that the spillover rate $\delta=0$. In section 7 , we will show how imperfect patent protection can be introduced.

We suppose that in each industry there are two firms which are involved both in production and R\&D. In each industry, the rival firms can be at different technology levels.

At each date $t$, an industry is described by a pair of technology levels $(k, k-n)$, where $k$ is the technological level of the leader and $k-n$ is the technological level of the follower. The variable $n$ is the gap between the two firms. This gap will be treated as a state variable. According to (6), the demand function in the industry $i$, given by $q_{i}(t)=c_{i}(t)=\frac{1}{p_{i}(t)}$, is of the constant elasticity type. Thus, whatever the nature of product market competition is, firms' equilibrium profit flows derived from competition in the product market depend only upon the technological gap $n$ and not upon the level $k$. We denote by $\pi_{n}$ the equilibrium profit flow of a firm which is $n$ steps ahead of it's rival (or $-n$ steps behind it if $n$ is negative).

As in Aghion et al. (1997), we suppose that the technological gap between firms cannot exceed one step. This assumption, which simplifies the model and allows analytical solutions, can be justified in two ways. First, it may be too costly (in terms of R\&D effort) to a firm to get more than one step ahead of it's rival. Second, as a firm moves one step ahead, it has no incentive to pay the renewal fee to maintain the protection on its old technology. The effective patent life is thus determined by the rhythm of the innovative process. The consequence of this assumption is that, at any time, each of the two firms in an industry can be in one and only one of the three following states: $n$ $\in\{-1,0,1\}$. A firm which is in the state $n=-1$ at some date is the technological follower while it's rival in the same industry, the technological leader, is in the state $n=1$. The corresponding unleveled industry is of the follower-leader type. When a firm is in the state $n=0$, both firms are at the same technological level and the corresponding leveled industry is of the 
neck-by-neck type. An industry can be, at any time, in just one of these two types. But, as time elapses, the type of an industry changes permanently.

We suppose that there exists an innovation process that allows a productivity increase by a parameter $\varphi(\varphi>1)$, equivalent to a reduction of unit cost. Thus a firm that makes an invention reduces its unit cost from a level $c$ to a level $\frac{c}{\varphi}$. We suppose that, by incurring an $\mathrm{R} \& \mathrm{D}$ cost of $\gamma(p)$, a firm moves one step ahead with Poisson hazard rate $p$. The R\&D technology is assumed to have decreasing returns. We assume that the $\mathrm{R} \& \mathrm{D}$ cost function $\gamma(p)$ is increasing, continuous and convex. We also assume that $\gamma(0)=0$.

We are now in position to describe how an industry evolves in time. Consider an infinitesimal period $[t, t+d t]$. Two cases must be considered depending on the type of the industry at the beginning of the period.

1. If an industry starts at date $t$ in the neck-by-neck state, both firms are at the existing cutting edge of technology. Three outcomes can occur during the period: i/ If both firms innovate during the period, neither will create a gap over the other and the industry will end the period as it began it in the neck-by-neck state; ii/ The same outcome prevails if neither firm innovates; iii/ If only one firm innovates, it will open a unit gap over its rival and the industry ends the period in the leader-follower state.

2. If an industry starts at date $t$ in the leader-follower type, then the technological leader has a unit gap over its rival and is at the cutting edge technology. Because the leader is at the cutting edge, if it succeeds in innovating, it lowers its unit production cost by the specified amount $\varphi$. For the follower, the situation is slightly different. We assume that with probability $\theta, 0 \leqslant \theta \leqslant 1$, a follower who succeeds in innovating is able to reach an understanding of the knowledge at the cutting edge, and so will be able to achieve exactly the same technology as the leader would obtain if it innovated. Thus, a successful follower can leapfrog the preceding leader with conditional probability $\theta$. However, with probability $1-\theta$, the follower will not master the knowledge at the cutting edge, and so, if it succeeds in innovating, it will obtain only the technology currently used by the leader. In this case, there is only a catching-up of the current leader's technology by the follower. The model captures thus the two polar cases corresponding respectively to leapfrogging $(\theta=1)$ and to step-by-step innovation $(\theta=0)$ as special cases of a more general situation where the intermediate cases, leapfrogging and catching-up, occur with the respective probabilities $\theta$ and $1-\theta$.

The possible evolutions of an industry starting from a leader-follower type 
can now be described.

i/ Suppose the follower does not succeed in innovating. If the leader succeeds in innovating, it will open up a gap of two steps, but according to our assumptions, the follower gets access to the previous leader's technology and the industry ends the period in the follower-leader position. If the leader does not succeed in innovating, the industry ends the period as it began it, namely in a follower-leader position. Therefore, when the follower does not succeed in innovating, it is preferable for the leader to avoid the R\&D cost.

ii/ Suppose now that the follower succeeds in innovating from the existing cutting edge. If the leader also innovates, the gap between them will be reduced to zero and the industry will end the period in the neck-by-neck position. However, if the leader fails to innovate, then the previous follower will have become the new leader and the industry will end the period in the leader-follower type (but with the role of firms being reversed).

iii/ Finally, suppose the follower succeeds in innovating, but not from the cutting edge. Then if the leader also innovates, it will maintain its gap of one step and the industry ends the period as it began it, namely in the leaderfollower type. However, if the leader fails to innovate, then its technological lead will be eliminated, and the industry will end the period in the neck-byneck position.

Innovative advances and hence economic growth occur at a rate determined by the $\mathrm{R} \& \mathrm{D}$ efforts denoted respectively $p_{-1}, p_{0}$ and $p_{1}$ according to whether the firm is in a follower position, a neck-by neck position or, a leadership position.

\section{The steady state equilibrium}

We focus on the determination of the Markov perfect and symmetric equilibrium of the game occurring at the steady state of the economy. A Markovian strategy for each firm in each industry specifies a choice of its R\&D effort as a function of its current gap ${ }^{6}$ and is time independant in the stationary state. Each firm chooses its R\&D efforts in each state in order to maximize its value function. Let $\mathrm{V}_{n}$ denote the value function of a firm starting from the state $n$. This value function gives the firm's expected discounted payoff

\footnotetext{
${ }^{6}$ Note that a firm which is ahead $(n=1)$ has no incentive do undertake R\&D due to our assumption of a maximal gap of 1 . Thus, we will find that at equilibrium $p_{1}=0$.
} 
in the game starting from the state in which it is $n$ steps ahead (or behind if $n<0)$ of its rival $(n=-1,0,1)$. These value functions satisfy the Bellman equations ${ }^{7}$.

\subsection{The value functions of the Markovian game}

Consider a period $[t, t+d t]$. Consider a firm that is in the state $n=-1$ at the starting date $t$. It obtains first a current profit given by $\pi_{-1} d t$. Second, by spending $\gamma\left(p_{-1}\right)$ in R\&D, it obtains an innovation during this period with probability $p_{-1} d t$. This innovation can be made either from the cutting edge technology with the probability $p_{-1} \theta d t$ or from its own technology with the probability $p_{-1}(1-\theta) d t$. In the first case, the firm leapfrogs the rival and starts the next period with the expected value $V_{1}$, while in the second case the firm succeeds only in catching-up the rival, starting the next period with the expected value $V_{0}$. Finally, with the complementary probability $1-p_{-1} d t$, the firm does not obtain any innovation during the period $[t, t+d t]$ and it starts the next period with the expected value $V_{-1}$. During the same period, the rival succeeds in innovating with the probability $\bar{p}_{1} d t$ where $\bar{p}_{1}, \bar{p}_{0}$ and $\bar{p}_{-1}$ denote the rivals' R\&D efforts. Figure 1 describes the corresponding game during the period $[t, t+d t]$. It also gives the discounted payoffs (gross of R\&D costs) of the follower at the end of this period.

The value function $V_{-1}$ of a follower satisfies the following Bellman equation :

$$
V_{-1}=\underset{p_{-1} \geq 0}{\operatorname{Max}}\left\{\left(\pi_{-1}-\gamma\left(p_{-1}\right)\right) d t+e^{-r d t}\left[V_{1} p_{-1} \theta d t+V_{0} p_{-1}(1-\theta) d t+V_{-1} \bar{p}_{1} d t+V_{-1}\left(1-\left(p_{-1}+\bar{p}_{1}\right) d t\right)\right]\right\}
$$

By using the first order approximation $e^{-\rho d t} \simeq 1-\rho d t$, and by keeping only the first order terms in $d t$, one obtains the equivalent equation:

$$
(1+r) V_{-1}=\underset{p_{-1} \geq 0}{\operatorname{Max}}\left\{\pi_{-1}-\gamma\left(p_{-1}\right)+p_{-1} \theta V_{1}+p_{-1}(1-\theta) V_{0}+\left(1-p_{-1}\right) V_{-1}\right\}
$$

For an interior solution, the first order condition is:

\footnotetext{
${ }^{7}$ See Fudenberg and Tirole (1991, Ch. 13).
} 


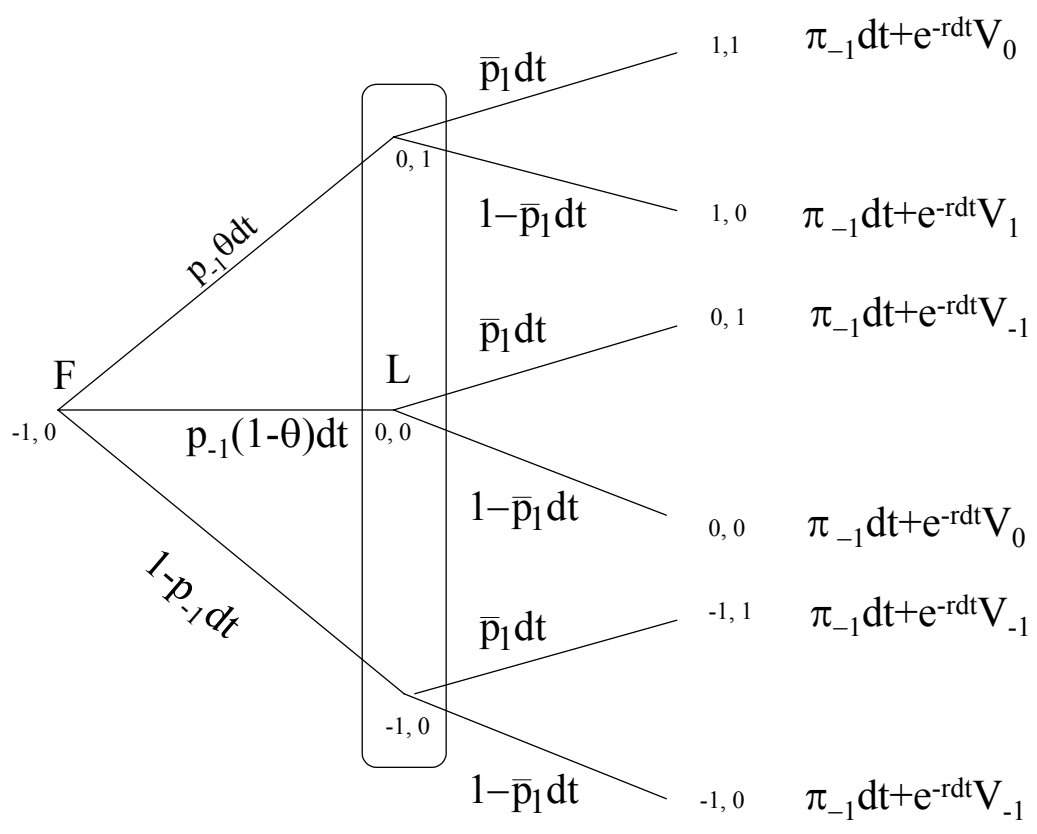

Figure 1: Determination of the follower's value function

$$
\gamma^{\prime}\left(p_{-1}\right)=\theta\left(V_{1}-V_{-1}\right)+(1-\theta)\left(V_{0}-V_{-1}\right)
$$

The interpretation of condition (9) is straightforward. The LHS is the R\&D marginal cost of the follower. The RHS gives the expected incremental revenue decomposed according whether the incremental revenue results from leapfrogging or from catching-up.

In the same way, one obtains the Bellman equations giving the value of a firm starting the period $[t, t+d t]$ at the respective states $n=1$ and $n=0$, and the corresponding first order conditions:

$$
\begin{gathered}
(1+r) V_{1}=\underset{p_{1} \geq 0}{\operatorname{Max}}\left\{\pi_{1}-\gamma\left(p_{1}\right)+\bar{p}_{-1}\left(\theta V_{-1}+(1-\theta) V_{0}\right)+\left(1-\bar{p}_{-1}\right) V_{1}\right\} \\
\gamma^{\prime}\left(p_{1}\right) \leq 0 \text { and } p_{1} \gamma^{\prime}\left(p_{1}\right)=0 \\
\left.(1+r) V_{0}=\underset{p_{0} \geq 0}{\operatorname{Max}}\left\{\pi_{0}-\gamma\left(p_{0}\right)+p_{0} V_{1}+\bar{p}_{0} V_{-1}+\left(1-p_{0}-\bar{p}_{0}\right) V_{0}\right)\right\}
\end{gathered}
$$




$$
\gamma^{\prime}\left(p_{0}\right)=V_{1}-V_{0}
$$

The symmetric-equilibrium conditions $\bar{p}_{-1}=p_{-1}, \bar{p}_{0}=p_{0}, \bar{p}_{1}=p_{1}$ are added to the preceding system of six equations ((8)-(13)). The unknowns of this system as the three value functions $V_{-1}, V_{0}, V_{1}$ and the three R\&D efforts $p_{-1}, p_{0}, p_{1}$. They depend of the following factors: $r$ (interest rate), $\theta$ (conditional probability to leapfrog), $\pi_{-1}$ (follower's current profit), $\pi_{0}$ (leveled firm's current profit), $\pi_{1}$ (leader's current profit), $\gamma(p)$ (R\&D cost to move one technological step ahead with Poisson hazard rate $p$ ). Note that, according to $(11)$, if $\gamma^{\prime}\left(p_{1}\right) \neq 0$, then, $p_{1}=0$. This results from the assumption of a maximal gap of one step.

\subsection{Industry structure and rate of growth}

The distribution of industries between leveled and unleveled ones in the steady-state is endogenous. Let denote by $\nu(\nu \in[0,1])$ the proportion of industries that are of the neck-by-neck type in the steady state. In order to determine the value of $\nu$, consider a period $[t, t+d t]$. During this time interval, two types of evolutions do occur.

In an industry of the neck-by-neck type (proportion $\nu$ ), a successful innovation made by only one of the two firms leads to an evolution towards an industry of the leader-follower type. This occurs with the probability: $2 p_{0} d t\left(1-p_{0} d t\right) \simeq 2 p_{0} d t$.

In an industry of the leader-follower type (proportion $1-\nu$ ), a successful innovation made either by both firms with a follower innovating from the cutting edge of technology or by only the follower who innovates from its own technology leads to an evolution towards an industry of the head-tohead type. This occurs with the probability: $\left(p_{-1} \theta d t p_{1} d t\right)+\left(p_{-1}(1-\theta) d t(1-\right.$ $\left.\left.p_{1} d t\right)\right) \simeq p_{-1}(1-\theta) d t$.

Since the distribution of industries remains stationary over time in the steady state, we must have:

$$
2 p_{0} \nu d t=p_{-1}(1-\theta)(1-\nu) d t .
$$

From this we obtain the value of $\nu$ which depends directly and indirectly on the parameter $\theta$ since the values of $p_{0}$ and $p_{-1}$ depend themselves on $\theta$ : 


$$
\nu=\frac{(1-\theta) p_{-1}}{2 p_{0}+(1-\theta) p_{-1}}
$$

The results are summarized in the following lemma:

Lemma 1 The proportion $\nu$ of industries that are neck-by-neck in the steady state is given by $\nu=\frac{(1-\theta) p_{-1}}{2 p_{0}+(1-\theta) p_{-1}}$, where $\theta$ is the probability to leapfrog the leader, conditional to a successful innovation by the follower, $p_{0}$ is the RESD effort by a neck-by neck firm and $p_{-1}$ is the RED effort by a follower. For a given $\theta$ in $[0,1], \nu$ is an increasing function of $p_{-1}$ and a decreasing function of $p_{0}$.

Note that for $\theta=0$, we obtain the same result as in Aghion et al. (1997). For $\theta=1$,we have $\nu=0$ insofar as $p_{0} \neq 0$. This means that in a strong leapfrogging situation, where a successful innovation by the follower gives it a leadership position, there are no industries that are of the neck-by-neck type.

We can now determine the instantaneous rate of growth of the economy in the steady state. Consider again a period $[t, t+d t]$. The growth rate $g$ of the economy is defined by

$$
g=\frac{d}{d t} \ln Q(t)=\frac{d}{d t} \ln C(t)=\frac{d}{d t} \int_{0}^{1} \ln c_{i}(t) d i
$$

Whatever each firm of an industry moves ahead by one step or the follower alone moves ahead by two steps, the rate of growth of the industry is given by $\ln \varphi$. This occurs in two ways.

First by the evolution from a neck-by-neck type towards the next neckby-neck type. Such evolution can be decomposed in two stages. In the first stage, the industry evolves from a neck-by-neck type (proportion $\nu$ ) to a leader-follower type. We denote $\ln \varphi_{1}$ the rate of growth in this first stage. The probability that such evolution occurs during the period $[t, t+d t]$ is given by $2 p_{0} d t\left(1-p_{0} d t\right) \simeq 2 p_{0} d t$. In the second stage, the industry evolves from a leader-follower type (proportion $1-\nu$ ) to a neck-by-neck type. We denote $\ln \varphi_{2}$ the rate of growth in this second stage. The probability that an industry of the leader-follower type moves to an industry of the neckand-neck type during the same period is given by $p_{-1}(1-\theta) d t\left(1-p_{1} d t\right) \simeq$ $p_{-1}(1-\theta) d t$. Of course, we have $\ln \varphi_{1}+\ln \varphi_{2}=\ln \varphi$. 
Second by the evolution from a leader-follower type to the next leaderfollower type, where the follower succeeds in leapfrogging the leader by moving ahead by two steps and the previous leader does not succeed in innovating. This evolution, which reverses the identity roles of the leader and follower, gives rise to a rate of growth of $\ln \varphi$. The probability that an industry of the leader-follower type (proportion $1-\nu$ ) moves to an industry of the next follower-leader type during the same period is given by $p_{-1} \theta d t\left(1-p_{1} d t\right) \simeq$ $p_{-1} \theta d t$.

The expected growth rate of the economy during the period $[t, t+d t]$ is thus given by:

$$
g d t=2 \nu p_{0} d t \ln \varphi_{1}+p_{-1}(1-\theta)(1-\nu) d t \ln \varphi_{2}+p_{-1} \theta(1-\nu) d t \ln \varphi
$$

From (16) we obtain the following expression of the rate of growth of the economy at the steady state:

$$
g=\left(2 \nu p_{0}+\theta p_{-1}(1-\nu)\right) \ln \varphi
$$

By substituting the value of $\nu$ given in the previous lemma, one obtains:

$$
g=\left[\frac{2 p_{0} p_{-1}}{2 p_{0}+(1-\theta) p_{-1}}\right] \ln \varphi
$$

Note again that $g$ is a direct and an indirect function of $\theta$. These results are summarized in the following lemma:

Lemma 2 For any $\theta \in[0,1]$, the growth rate at the the steady state of the economy $g$ is given by (19). It is an increasing function of both the R\&D effort $p_{-1}$ of a follower and the REBD effort $p_{0}$ of a neck-by-neck firm. For fixed values of $p_{0}$ and $p_{-1}, g$ is an increasing function of $\theta$.

Note that in the case $\theta=0$, which corresponds to the catching-up setting implicit to the step-by-step innovation analyzed in Aghion et al. (1997), we obtain $g=\frac{2 p_{0} p_{-1}}{2 p_{0}+p_{-1}} \ln \varphi$. The case $\theta=1$ corresponds to the leapfrogging situation in which a successful follower obtains a technological leadership. In this case we have $\nu=0$ and thus $g=p_{-1} \ln \varphi$. The rate of growth is directly proportional to the follower's R\&D effort whenever $\theta=1$.

We have now to compute the solution of the non linear system $(8-13)^{8}$.

\footnotetext{
${ }^{8}$ Note that a solution of this system exists if the R\&D cost function is continuous
} 


\section{The solution for a quadratic $R \& D$ cost func- tion}

Suppose that the R\&D cost function is given by: $\gamma(p)=\frac{1}{2} p^{2}$. We define the parameters $a \equiv \pi_{1}-\pi_{0}$ and $b \equiv \pi_{0}-\pi_{-1}$. The parameters $a$ and $b$ play an important role in what follows. They measure the short run profit flow increments respectively associated to gaining the lead and to catching up. They are directly linked to the short term determinants of an industry evolution (Budd et al. (1993)). The values of these parameters depend on $\varphi$ and on the intensity of product market competition which we denote by $\rho$. In the next section we will explore more fully how $\rho$ affects $a$ and $b$ and hence the short run incentives to innovate.

After tedious but straightforward substitutions, the system $(8-13)$ leads to a system of two equations having the variables $p_{0}$ and $p_{-1}$ as solutions:

$$
\begin{gathered}
2 r p_{0}+(1+2 \theta)\left(p_{0}\right)^{2}+2 \theta\left(p_{-1}\right)^{2}-2 \theta^{2} p_{0} p_{-1}-2 a=0 \\
2 r\left(p_{-1}-\theta p_{0}\right)-(1+2 \theta)\left(p_{0}\right)^{2}+\left(p_{-1}\right)^{2}+2 p_{0} p_{-1}-2 b=0
\end{gathered}
$$

In order to make further progress it is necessary to make a simplifying assumption about the interest rate. In the remainder of the paper we will take $r=0$.

By transforming the preceding system, one obtains:

$$
\begin{gathered}
\left(1-\theta^{2}\right) p_{0}=\frac{2(a+b)-\left(p_{-1}\right)^{2}(1+2 \theta)}{2 p_{-1}} \\
(1+2 \theta) p_{0}=\frac{\theta(\theta+2)}{1+2 \theta} p_{-1}+\sqrt[2]{\left(\frac{\theta(\theta+2)}{1+2 \theta} p_{-1}\right)^{2}+2(a-2 \theta b)}
\end{gathered}
$$

In each of the two polar cases, $\theta=0$ and $\theta=1$ the analytic solution of the system is immediate. For intermediate values of $\theta$ we establish an existence result.

and convex. To get a sketch of the proof of this existence, consider the vector $X=$ $\left(p_{-1}, p_{0}, p_{1}, V_{-1}, V_{0}, V_{1}\right)$ and write the system $(8-13)$ as $F(X)=0$, where $F$ is a continuous and convex function from $R^{6+}$ to $R^{6}$. Choose a convex compact set $B \subset R^{6+}$ sufficiently large to insure that $F$ is defined in $B$ and have values in $B$. Now, consider the function $G(X)=F(X)+X$. By the Brouwer fixed point theorem, there exists a value of $X$ such that $G(X)=X$. Such a value of $X$ is a solution of the system $(8-13)$. 


\subsection{Pure Catch-up: $\theta=0$.}

By solving (23) and substituting the solution into (22) it follows that

$$
p_{0}=\sqrt{2 a} ; p_{-1}=\sqrt{2(2 a+b)}-\sqrt{2 a}
$$

\subsection{Pure Leapfrog: $\theta=1$.}

By solving (22) and substituting the solution into (23), we obtain:

$$
p_{0}=\frac{1}{3}\left[\sqrt{\frac{2}{3}(a+b)}+\sqrt{\frac{2}{3}(4 a-5 b)}\right] ; p_{-1}=\sqrt{\frac{2}{3}(a+b)}
$$

It is interesting to notice that if $b=0$ then $p_{0}=p_{-1}$. In the next section we show that $b=0$ when Bertrand competition prevails in the market.

Notice that, in order for the value of $p_{0}$ defined by (25) to be well defined we need to ensure that

$$
a>\frac{5}{4} b
$$

Although, as pointed out above, we can generally assume that $a>b$, there is no guarantee that the inequality in (26) will generally hold. We will show in the next section that (26) holds if, either the cost gap $\varphi$ is sufficiently large or, the intensity of competition $\rho$ is sufficiently high.

We can turn now to the intermediate values of $\theta$ for which an analytical solution is more difficult to obtain.

\subsection{Intermediate values: $0<\theta<1$.}

Do there exist a positive solution of the system (22-23) whatever the values of the parameters $a$ and $b$ ?

Equation (22) makes $p_{0}$ a strictly decreasing function of $p_{-1}$. Moreover, $p_{0}$ is positive if $p_{-1}<\sqrt{\frac{2(a+b)}{1+2 \theta}}$ and $p_{0} \rightarrow \infty$ as $p_{-1} \rightarrow 0$.

Equation (23) makes $p_{0}$ a strictly increasing function of $p_{-1}$. If $a \geq$ $2 \theta b$, the function is well defined and convex for all non-negative values of $p_{-1}$. Clearly, in this case, the system (22) and (23) has a unique positive 
solution for $p_{0}$ and $p_{-1}$. If $a<2 \theta b$ then the value of $p_{0}$ defined by (23) is well defined only for $p_{-1} \geq \frac{1+2 \theta}{\theta(\theta+2)} \sqrt{2(2 \theta b-a)}$. It is straightforward to show that the inequality (26) is a sufficient condition to guarantee that the equations (22) and (23) has a unique positive solution for $p_{0}$ and $p_{-1}$ for all values of $\theta \in[0,1]$. Thus we have established the following existence result:

Theorem 3 If $a>\frac{5}{4} b$ then the system given by equations (22) and (23) has a unique positive solution, $p_{0}$ and $p_{-1}$, for any value of $\theta \in[0,1]$.

The solution of the system (22-23) depends finally on the following variables: $a, b$ and $\theta$. But $a$ and $b$ are themselves are dependent on two parameters: the degree of rivalry $\rho$ in the product market and the cost reduction $\varphi$ allowed by a one step move innovation. Before undertaking the comparative static analysis of the solution $\left(p_{0}, p_{-1}\right)$ of the system $(22-23)$ with respect to the parameters $\rho, \theta$ and $\varphi$, it is important to examine the short run incentives to innovate given by the profit increments $a$ and $b$. As a point of reference we briefly explore how the degree of rivalry $\rho$ in the product market and the cost reduction $\varphi$ affect the individual firm short-run incentives to innovate in different types of industries.

\section{Short-run effects of rivalry on innovation}

In our model, each industry is represented as an homogeneous product duopoly. The inverse demand curve is given by:

$$
p=\frac{1}{q_{1}+q_{2}}
$$

where $q_{i}$ is output of firm $i$. We examine the short-run equilibrium profits of the market game in which the industry is in either a leader-follower type or a neck-by-neck type. We denote the ratio of the the unit production cost of the most efficient firm to the unit cost of the least efficient firm by $1-\Psi$ where $0 \leq \Psi<1$. A neck-by-neck industry is represented by $\psi=0$, while an unleveled industry is represented by $\psi \equiv \frac{\varphi-1}{\varphi}>0$. One way to capture the intensity of competition (or the degree of rivalry) in the product market is to use the conjectural variation approach, according to which, when maximizing profits, firm $i$ makes the conjecture that it's rival $j$ will react accordingly through $\frac{d q_{j}}{d q_{i}}=-\rho$. The parameter $\rho \in[0,1]$ can serve as a measure of the 
degree of rivalry or the intensity of competition in the product market, since it satisfies the reallocation property emphasized by Boone (2001b). We assume that the two firms use the same conjectures. The value $\rho=0$ corresponds to Cournot behavior and $\rho=1$ to Bertrand behavior.

\subsection{Flow profits.}

In a neck-by-neck industry $(\Psi=0)$ the two firms are always active at the equilibrium of the market game. The equilibrium flow profits of each firm in a neck-by-neck industry are given by:

$$
\pi_{0}(\rho)=\frac{1-\rho}{4}(0 \leq \rho \leq 1)
$$

The individual flow profits $\pi_{0}(\rho)$ is a strictly decreasing function of $\rho$. We will refer to this as the level effect: An increased rivalry in the product market lowers the absolute profits of the firms acting in a leveled industry.

In a leader-follower type industry $(\Psi>0)$, an interior solution where the two firms are active exists only if $\rho<1-\Psi$. Whenever $\rho \geq 1-\Psi$ a boundary solution prevails where only the most efficient firm is active. The equilibrium profit flows are given by:

$$
\begin{aligned}
& \pi_{-1}(\rho, \Psi)=\left\{\begin{array}{ccc}
\frac{1-\rho}{4} \frac{\left[1-\frac{\Psi}{1-\rho}\right]^{2}}{\left[1-\frac{\Psi}{2}\right]^{2}} & \text { if } & 0 \leq \rho \leq 1-\Psi \\
0 & \text { if } & 1-\Psi \leq \rho \leq 1
\end{array}\right. \\
& \pi_{1}(\rho, \Psi)=\left\{\begin{array}{cll}
\frac{(1-\rho)}{4} \frac{\left[1+\frac{\psi \rho}{1-\rho}\right]^{2}}{\left[1-\frac{\psi}{2}\right]^{2}} & \text { if } & 0 \leq \rho \leq 1-\Psi \\
\Psi & \text { if } & 1-\Psi \leq \rho \leq 1
\end{array}\right.
\end{aligned}
$$

The equilibrium flow profits $\pi_{-1}(\rho, \Psi)$ of the follower is a decreasing function of the rivalry index $\rho$ when $\rho \in[0,1-\Psi]$. For higher levels of rivalry $(\rho \geq 1-\Psi)$ the follower becomes inactive.

The properties of the equilibrium flow profits of the leader $\pi_{1}(\rho, \Psi)$ are slightly different. One has to distinguish two cases, according to whether the relative cost parameter given by $\Psi$ is lower or higher to $\frac{1}{2}$.

When $\Psi<\frac{1}{2}$, the productivity improvement $\varphi$ brought by a move of one step ahead is such that $\varphi<2$. Each innovation reduces the unit cost by less than half. In this case, the profit flow of the leader $\pi_{1}(\rho, \Psi)$ is a nonmonotone function of $\rho$. It is first decreasing with $\rho$ when $\rho \in\left[0, \frac{1-2 \Psi}{1-\Psi}\right]$, then 
it increases with $\rho$ when $\rho \in\left[\frac{1-2 \Psi}{1-\Psi}, 1-\Psi\right]$ before becoming independent of $\rho$ when the leader becomes a monopolist.

When $\Psi \geq \frac{1}{2}$ the productivity improvement $\varphi$ is such that $\varphi \geq 2$. In this case, a leader benefits from its cost advantage all the more the degree of rivalry is higher. The flow profits $\pi_{1}(\rho, \Psi)$ is an increasing function of $\rho$ when $\rho \in[0,1-\Psi]$.

All these properties allow us to introduce the profit spreads.

\subsection{Spread effects of competition.}

We define the ratios $\alpha(\rho, \Psi)$ and $\beta(\rho, \Psi)$ by $\alpha(\rho, \Psi) \equiv \frac{\pi_{1}(\rho, \Psi)}{\pi_{0}(\rho)}$ and $\beta(\rho, \Psi) \equiv$ $\frac{\pi_{-1}(\rho, \Psi)}{\pi_{0}(\rho)}$. These ratios measure the spread effects of competition, taking the profits in a leveled industry as a benchmark. Suppose that the degree of rivalry in the product market is less than maximal $(\rho<1)$. By using equations (29) to (31), one obtains:

$$
\begin{aligned}
& \alpha(\rho, \Psi)=\left\{\begin{array}{cll}
\frac{\left[1+\frac{\Psi \rho}{1-\rho}\right]^{2}}{\left[1-\frac{\Psi}{2}\right]^{2}} & \text { if } & 0 \leq \rho \leq 1-\Psi \\
\frac{4 \Psi}{1-\rho} & \text { if } & 1-\Psi \leq \rho<1
\end{array}\right. \\
& \beta(\rho, \Psi)=\left\{\begin{array}{cll}
\frac{\left[1-\frac{\Psi}{1-\rho}\right]^{2}}{\left[1-\frac{\Psi}{2}\right]^{2}} & \text { if } & 0 \leq \rho \leq 1-\Psi \\
0 & \text { if } & 1-\Psi \leq \rho<1
\end{array}\right.
\end{aligned}
$$

It is easy to check the following properties.

Property 1: $0 \leq \beta(\rho, \Psi)<1<\alpha(\rho, \Psi) \forall \rho \in[0,1[$ and $\forall \Psi \in] 0,1[$.

This property states that the relative gain that a successful follower obtains by catching-up the leader is lower than the relative gain of a neck-byneck firm that moves one step ahead. Moreover, the profit of a follower is always lower than the profit of a neck-by-neck firm. This means that the short term profit incentive to invest in $R \& D$ is lower for a follower than for a head-to-head firm when the follower hopes to succeed in innovating by only catching up the leader.

Property 2: $\alpha(\rho, \Psi)$ is an increasing function of $\rho \in[0,1[$ and $\beta(\rho, \Psi)$ is a decreasing function of $\rho \in[0,1-\Psi]$.

This property states that the spread effects are both increasing with the degree of rivalry in the product market. On the one hand, the short term 
profit incentive of a firm to move away one step ahead from a neck-by-neck competition increases with the degree of rivalry in the market. This is the escape from competition effect. On the other hand, the short term incentive to innovate of a follower who expects to catch-up the leader increases with the degree of rivalry because the laggard firm's profit decreases as $\rho$ increases.

In order to evaluate the overall effect of competition on the short-run incentives to innovate, we decompose the overall effect of $\rho$ onto the level effect and the spread effects. Recall that the short run incentives to innovate are given by the incremental profits $a(\rho, \Psi) \equiv \pi_{1}(\rho, \Psi)-\pi_{0}(\rho)$ and $b(\rho, \Psi) \equiv$ $\pi_{0}(\rho)-\pi_{-1}(\rho, \Psi)$. These parameters represent what are called respectively the escape from competition incentive to innovate $(a(\rho, \Psi))$ and the catchingup incentive to innovate $(b(\rho, \Psi))$. Note that the sum $a(\rho, \Psi)+b(\rho, \Psi) \equiv$ $\pi_{1}(\rho, \Psi)-\pi_{-1}(\rho, \Psi)$ represents the leapfrogging incentive to innovate.

\subsection{Decomposition of the overall effect of competition.}

One can write $a(\rho, \Psi)=\pi_{0}(\rho) A(\rho, \Psi)$ where $A(\rho, \Psi)=\alpha(\rho, \Psi)-1>0$ and $b(\rho, \Psi)=\pi_{0}(\rho) B(\rho, \Psi)$ where $B(\rho, \Psi)=1-\beta(\rho, \Psi)>0$. A variation of the intensity of competition $\rho$ has therefore two effects on the short run incentives to innovate.

The first effect of $\rho$ on $a(\rho, \Psi)$ and $b(\rho, \Psi)$ is obtained through $\pi_{0}(\rho)$. This effect, called the level effect, is negative : $\frac{\partial \pi_{0}(\rho)}{\partial \rho}<0$ (see 28).

The second effect of $\rho$ on $a(\rho, \Psi)$ and $b(\rho, \Psi)$ is obtained through the respective terms $A(\rho, \Psi)$ and $B(\rho, \Psi)$. These effects, called the spread effects, are positive: $\frac{\partial A(\rho, \Psi)}{\partial \rho}>0$ and $\frac{\partial B(\rho, \Psi)}{\partial \rho}>0$ (Property 2).

It appears that, taken together, these two effects certainly lower the flow profits of the least efficient firm but may or may not increase the profits of the most efficient firm.

One can easily check that:

(a) $a(\rho, \Psi)>b(\rho, \Psi) \forall \in[0,1]$. The escape from competition incentive to innovate dominates the catching-up incentive to innovate.

(b) $a(\rho, \Psi)$ is a strictly increasing function of $\rho \in[0,1]$. The escape from competition incentive to innovate increases with the degree of rivalry in the product market.

(c) If $\Psi>0.8(\Leftrightarrow \varphi>5)$, then $b(\rho, \Psi)$ is a strictly decreasing function of $\rho \in[0,1]$. When the cost reduction brought by an innovation is high, the catching-up incentive to innovate decreases with the degree of rivalry. 
(d) If $\Psi \leq 0.8(\Longleftrightarrow \varphi \leq 5)$, then $b(\rho, \Psi)$ is no more a monotonic function. It increases strictly with $\rho$ in the interval $\left[0, \frac{4-5 \psi}{4-\psi}\right)$ and it decreases strictly with $\rho$ in the interval $\left(\frac{4-5 \psi}{4-\psi}, 1\right]$. Note that $b(\rho=1, \Psi)=0 \forall \Psi$.

(d) $a(\rho, \Psi)+b(\rho, \Psi)$ is a strictly increasing function of $\rho$ on $[0,1-\psi]$. The leapfrogging incentive to innovate increases with the degree of rivalry in the market, as long as both firms are active.

(e) $a(\rho, \Psi)>\frac{5}{4} b(\rho, \Psi)$ if and only if $\psi>\frac{4(1-\rho)}{7 \rho+11}$. Notice that if $\psi>\frac{4}{11}$ ( $\Leftrightarrow \varphi>\frac{11}{7}$ ) then $a(\rho)>\frac{5}{4} b(\rho) \forall \rho \in[0,1]$. Since we have shown that an existence of a positive solution $\left(p_{0}, p_{-1}\right)$ of the system $(22-23)$ requires $a>\frac{5}{4} b$, the existence of a positive solution for any value of $\rho \in[0,1]$ is insured by imposing the condition $\varphi>\frac{11}{7}$.

(f) $A(\rho, \Psi)$ is a strictly increasing function on $\rho \in[0,1] ; B(\rho, \Psi)$ is strictly increasing of $\rho \in[0,1-\psi)$ and is independent of $\rho$ when $\rho \in[1-\psi, 1]$. Therefore, the spread effects of competition are increasing functions of the degree of rivalry as long as both firms remain active in the market.

\section{$6 \quad$ Effects of rivalry on innovation and growth}

We will assume throughout this section that $\varphi>\frac{11}{7}$. This will guarantee that $\Psi>\frac{4}{11}$ and so (26) holds for all $\rho \in[0,1]$. Our results are obtained through a mixture of numerical simulation and analytical methods. In the numerical simulations we have used the values of $\Psi=0.4,0.6$ and $0.8 .^{9}$ These span a wide range of cases consistent with the requirement that $\Psi>\frac{4}{11}$ and $\Psi \leq 0.8$. All our qualitative predictions hold for these values.

Our investigation will proceed in two parts. We begin by examining the overall effects of an increase in competition on innovation and growth. We will show that in the catching-up case $(\theta=0)$ an increase in the degree of rivalry will increase growth when competition is weak, but decrease growth when competition is intense. In the weak leapfrogging case $(\theta=1)$, an increase in competition will always increase growth. We then decompose the effects of competition into the two separate effects - the level effect and the spread effect. We show that the former always reduces innovation and growth and the latter always increases it.

\footnotetext{
${ }^{9}$ These correspond to values for $\varphi$ of $\frac{5}{3}, \frac{5}{2}$, and 5 respectively.
} 


\subsection{Overall effects of an increase in rivalry}

To obtain insights we will focus on the two extreme cases of a step-by-step process innovation, namely catching-up $(\theta=0)$ and leapfrogging $(\theta=1) \cdot{ }^{10}$

\subsubsection{Catching-up: $\theta=0$}

From (24) and the results obtained in subsection 5.1, we see that an increase in competition always increases $p_{0}$. Numerical simulations reveal that $p_{-1}(\rho, \Psi, \theta=0)$ is strictly increasing in $\rho$ whenever we have an interior solution - i.e. whenever $\rho<1-\psi$. Taken together these results show that the growth rate $g(\rho, \Psi, \theta=0)$ is an increasing function of $\rho$ whenever $\rho<1-\psi$. However it is possible to prove analytically that both $p_{-1}(\rho, \Psi, \theta=0)$ and the growth rate $g(\rho, \Psi, \theta=0)$ are strictly decreasing functions of $\rho$ for $\rho>1-\psi .^{11}$

The intuition behind these results is clear. When firms are in a leveled industry, the short term incentive to escape from competition is given by $a(\rho, \Psi)$ which is an increasing function of $\rho$. However, when firms are in an unleveled industry, the immediate incentive of the follower to innovate is given by $b(\rho, \Psi)$. This is initially increasing in $\rho$. But when competition is very intense $(\rho \geq 1-\Psi)$, the follower's profits $\pi_{-1}(\rho, \Psi)$ are driven to zero, and so $b(\rho, \Psi)=\pi_{0}(\rho, \Psi)$ which is a strictly decreasing function of $\rho$.

\subsubsection{Leapfrogging: $\theta=1$}

From (25) and the results obtained in subsection 5.1, we see that an increase in competition always increases $p_{-1}(\rho, \Psi, \theta=0)$ and hence the growth rate $g(\rho, \Psi, \theta=0)$. The intuition is clear. When $\theta=1$, the industry is always in an unleveled situation. The incentive to escape is given by $a(\rho, \Psi)+b(\rho, \Psi) \equiv \pi_{1}(\rho, \Psi)-\pi_{-1}(\rho, \Psi)$ which is a strictly increasing function of $\rho$. For completeness we note that numerical simulations reveal that $p_{0}(\rho, \Psi, \theta=0)$ is strictly increasing in $\rho$ for $\rho<1-\psi$. It is easy to see that $p_{0}(\rho, \Psi, \theta=0)$ is also strictly increasing in $\rho$ for $\rho \geq 1-\psi$.

These results are summarized as follows:

\footnotetext{
${ }^{10}$ In the next section we will examine more fully how intermediate values of $\theta$ affect innovation and growth.

${ }^{11}$ It is possible to show that: when $\psi=0.4$ then $p_{-1}(\rho=1)>p_{-1}(\rho=0)$; when $\psi=0.6$, then $p_{-1}(\rho=0) \approx p_{-1}(\rho=1)$; and when $\psi=0.8$ then $p_{-1}(\rho=1)<p_{-1}($ $\rho=0)$. Table 1 that appears below confirms these conclusions.
} 
Theorem 4 In the pure catching-up case $(\theta=0)$, the overall effect of competition on growth is positive if and only if the degree of rivalry $\rho$ is below the threshold $\psi \equiv \frac{\varphi-1}{\varphi}$. In the pure leapfrogging case $(\theta=1)$, the overall effect of competition on growth is positive for all values of $\rho$ in $[0,1]$.

\subsection{Decomposing the overall effect of increased rivalry}

We have shown that an increase in rivalry $\rho$ would have two effects on profits: (i) the level effect, i.e. the reduction in $\pi_{0}(\rho, \Psi)$; (ii) the spread effect, i.e. the increase in $A(\rho, \Psi)$ and $B(\rho, \Psi)$. We now want to isolate the impact on innovation of these two separate effects. More precisely, we want to examine the effects on innovation of reductions in $\pi_{0}$ holding $A$ and $B$ constant, and the effect on innovation of increases in $A$ and $B$ holding $\pi_{0}$ constant. In order to do this, define the variables $q_{0}$ and $q_{-1}$ by the equations:

$$
p_{0}=\sqrt{\pi_{0}} \cdot q_{0} ; p_{-1}=\sqrt{\pi_{0}} \cdot q_{-1}
$$

Substituting these into (22) and (23), we obtain

$$
\begin{gathered}
\left(1-\theta^{2}\right) q_{0}=\frac{2(A+B)-\left(q_{-1}\right)^{2}(1+2 \theta)}{2 q_{-1}} \\
(1+2 \theta) q_{0}=\frac{\theta(\theta+2)}{1+2 \theta} q_{-1}+\sqrt[2]{\left(\frac{\theta(\theta+2)}{1+2 \theta} q_{-1}\right)^{2}+2(A-2 \theta B)}
\end{gathered}
$$

Notice also that

$$
A>\frac{5}{4} B \Leftrightarrow a>\frac{5}{4} b
$$

Therefore (22) and (23) have a unique positive solution iff (37) and (38) have a unique positive solution. Notice that (37) and (38) depend only on the spread variables $A$ and $B$.

To isolate the impact on innovation of the spread effect of increased competition we examine the effects of an increase in $\rho$ on $A$ and $B$ - and hence, via (37) and (38) on $q_{0}$ and $q_{-1}$. To isolate the impact on innovation of the level effect of increased competition, we hold $A$ and $B$ constant and, using (36) examine the impact of increases in $\rho$ on $q_{0}$ and $q_{-1}$ via the reduction in $\pi_{0}$. We therefore immediately obtain the following result: 
Theorem 5 In both the pure catching-up and leapfrogging cases, the level effect of increased rivalry always lowers innovation and growth

A more substantive issue concerns the impact of the spread effect on innovation and growth. To address this issue it is useful to consider again the two extreme cases.

Pure catching-up case: $\theta=0$

Obviously the expressions for $q_{0}$ and $q_{-1}$ are the exact analogues for $p_{0}$ and $p_{-1}$ in (24) with $A$ and $B$ replacing $a$ and $b$ respectively. From the results in section 5.1 it is immediately clear that $q_{0}$ is a strictly increasing function of $\rho$. Numerical simulations reveal that $q_{-1}$ is a strictly increasing function of $\rho$ when $\rho<1-\psi$. It is also fairly straightforward to prove analytically that $q_{-1}$ is also a strictly increasing function of $\rho$ when $\rho \geq 1-\psi$. Hence the spread effect certainly increases growth in this case.

Pure Leapfrogging case: $\theta=1$

Here the analogue of (25) applies. It follows immediately that the spread effect increases both $q_{-1}$ and the growth rate. For completeness, we also confirmed by numerical methods that $q_{0}$ is a strictly increasing function of $\rho$ when $\rho<1-\psi$. It is very straightforward to prove analytically that $q_{-1}$ is also a strictly increasing function of $\rho$ when $\rho \geq 1-\psi$.

Hence we have established the following result:

Theorem 6 In both the pure catching-up and leapfrogging cases the spread effect of increased rivalry increases innovation and growth.

\subsection{The effects of rivalry on the dynamics of competi- tion}

As mentioned in the introduction, it is interesting to ask how the degree of product market competition (or intensity of rivalry) affects the competitiveness of industries as reflected in the frequency with which they are in the neck-and-neck equilibrium. That is, we wish to know how $\rho$ affects $\nu$.

We know that in the pure leapfrogging case - where $\theta=1$ - then $\nu=0$ and so the industry structure is unaffected by the nature of rivalry.

Consider then the catch-up case, $\theta=0$. We know that $\nu$ is an increasing function of $p_{-1}$ and a decreasing function of $p_{0}$ (Lemma). We also know 
that $p_{0}$ is a strictly increasing function of $\rho$, while $p_{-1}$ is strictly increasing in $\rho$ whenever $\rho<1-\psi$ and strictly decreasing in $\rho$ whenever $\rho>1-\psi$. Taken together these results immediately imply that $\nu$ is a strictly decreasing function of $\rho$ for $\rho>1-\psi$. It is straightforward to confirm by numerical simulation that, for the three values of $\psi$ considered above, $\nu$ is also a strictly decreasing function of $\rho$ for $\rho<1-\psi$. Hence we have the following result:

Theorem 7 An increase in the intensity of rivalry lowers the fraction of neck-and-neck industries.

This is a fairly familiar result showing that forces that increase static competition may have adverse effects on competition in a dynamic context.

\section{$7 \quad$ Effects of knowledge and technological flows}

\subsection{Effects of knowledge flows $\theta$}

We begin by examining the effects of $\theta$ on growth. In trying to understand this issue we will focus on the two extreme cases of Cournot competition $(\rho=0)$ and Bertrand competition $(\rho=1)$. For each of these cases, and for the values of $\psi$ considered above, it is straightforward to compute directly what happens at the extreme cases where $\theta=0$ and $\theta=1$.

The following table 1 conveys the essential information.

What we see from this table is that as $\theta$ increases: (i) $p_{0}$ falls; (ii) $p_{-1}$ increases; (iii) $g$ increases.

It is straightforward to verify that the behavior of these three variables is monotonic across the range of intermediate values of $\theta$. The following diagrams (figs. 2-6) illustrate. 


\begin{tabular}{|c|c|c|c|c|c|c|c|c|c|c|c|c|}
\hline$\psi$ & \multicolumn{4}{|c|}{ Case 1: $\psi=0.4$} & \multicolumn{4}{|c|}{ Case $2: \psi=0.6$} & \multicolumn{4}{|c|}{ Case 3: $\psi=0.8$} \\
\hline 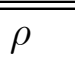 & \multicolumn{2}{|c|}{$\overline{0}$} & \multicolumn{2}{|c|}{1} & \multicolumn{2}{|c|}{ 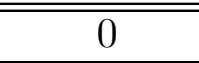 } & \multicolumn{2}{|c|}{1} & \multicolumn{2}{|c|}{ 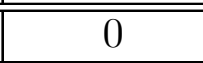 } & \multicolumn{2}{|c|}{ 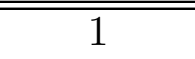 } \\
\hline$\overline{\overline{\pi_{0}}}$ & \multicolumn{2}{|c|}{0.25} & \multicolumn{2}{|c|}{ 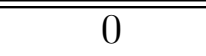 } & \multicolumn{2}{|c|}{0.25} & \multicolumn{2}{|c|}{$\overline{0}$} & \multicolumn{2}{|c|}{0.25} & \multicolumn{2}{|c|}{ 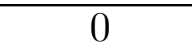 } \\
\hline$\pi_{1}$ & \multicolumn{2}{|c|}{0.39} & \multicolumn{2}{|c|}{0.4} & \multicolumn{2}{|c|}{0.51} & \multicolumn{2}{|c|}{0.6} & \multicolumn{2}{|c|}{0.69} & \multicolumn{2}{|c|}{0.8} \\
\hline$\pi_{-1}$ & \multicolumn{2}{|c|}{0.14} & \multicolumn{2}{|c|}{0} & \multicolumn{2}{|c|}{0.08} & \multicolumn{2}{|c|}{0} & \multicolumn{2}{|c|}{0.03} & \multicolumn{2}{|c|}{0} \\
\hline$a$ & \multicolumn{2}{|c|}{0.14} & \multicolumn{2}{|c|}{0.4} & \multicolumn{2}{|c|}{0.26} & \multicolumn{2}{|c|}{0.6} & \multicolumn{2}{|c|}{0.44} & \multicolumn{2}{|c|}{0.8} \\
\hline$b$ & \multicolumn{2}{|c|}{0.11} & \multicolumn{2}{|c|}{0} & \multicolumn{2}{|c|}{0.17} & \multicolumn{2}{|c|}{0} & & & & \\
\hline$\overline{\overline{\theta \theta}}$ & 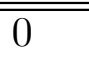 & 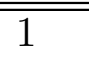 & 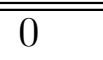 & 1 & 0 & 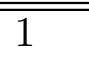 & 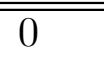 & 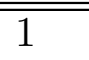 & 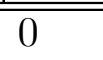 & 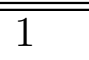 & 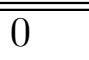 & 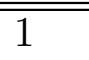 \\
\hline$p_{0}$ & 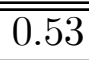 & 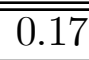 & 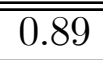 & 0.52 & 0.72 & 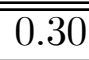 & 1.10 & 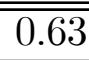 & 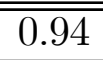 & 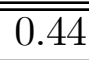 & 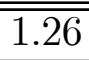 & 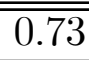 \\
\hline$p_{-1}$ & 0.35 & 0.41 & 0.37 & 0.52 & 0.45 & 0.53 & 0.45 & 0.63 & 0.55 & 0.67 & 0.52 & 0.73 \\
\hline$g$ & 0.14 & 0.21 & 0.16 & 0.27 & 0.31 & 0.49 & 0.35 & 0.58 & 0.68 & 1.1 & 0.69 & 1.2 \\
\hline$\nu$ & 0.25 & 0 & 0.17 & 0 & 0.24 & 0 & 0.17 & 0 & 0.23 & 0 & 0.17 & 0 \\
\hline
\end{tabular}

Table 1: Values of innovation and growth for $\theta=0$ and $\theta=1, \rho=0$ and $\rho=1$ for different values of $\Psi$.

The intuition behind these results is straightforward. The easier it is for firms to leapfrog one another, the greater is the incentive for the follower to innovate, and the lower is the incentive of firms in a neck-and-neck situation to try to establish a position of dominance. Although these effects have opposing impacts on the growth rate, we see from the formula for $g$ given in (19) that as $\theta$ increases, the growth rate is increasingly dominated by $p_{-1}$ which explains why growth is also increasing in $\theta$.

Notice also that our conclusions are in contrast to those of Aghion et al. (1997) who argue that growth is faster under catching-up than leapfrogging.

Turning to the impact of $\theta$ on $\nu$, the proportion of neck-and-neck industries, we know that $\nu$ is positive when $\theta=0$ and equal to zero when $\theta=1$. In this case the behavior of $\nu$ is NOT monotonic for intermediate values of $\theta$. Instead $\nu$ initially increases and then decreases with $\theta$ (see fig. 7 ). 


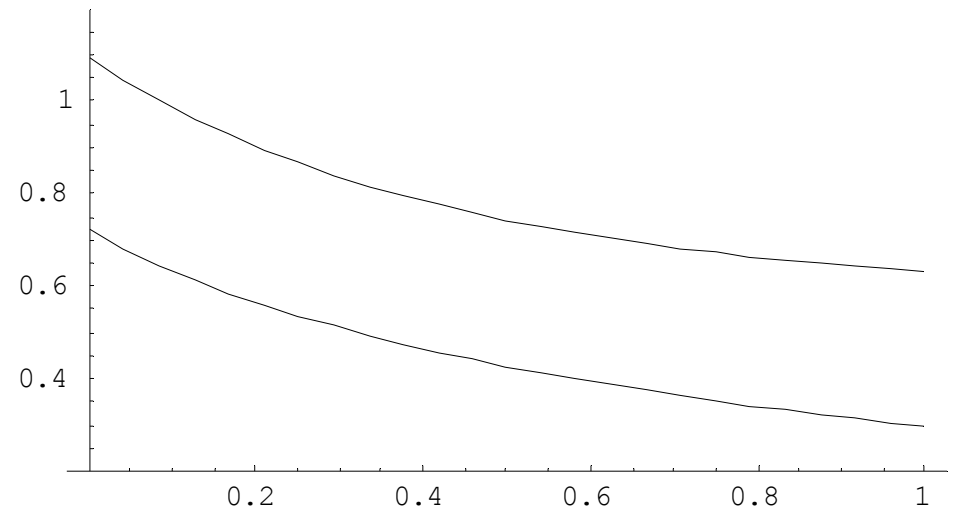

Figure 2: Fig. 2: $p_{0}(\theta, \rho)$ for $\rho=0$ (curve below) and $\rho=1(\psi=0.6)$.

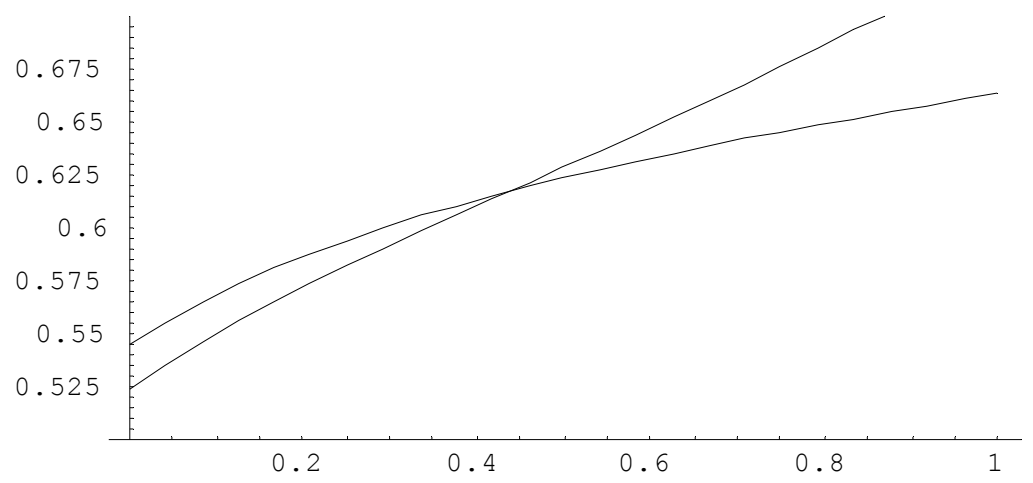

Figure 3: Fig. 3: $p_{-1}(\theta, \rho)$ for $\rho=0$ and $\rho=1(\psi=0.8)$. 


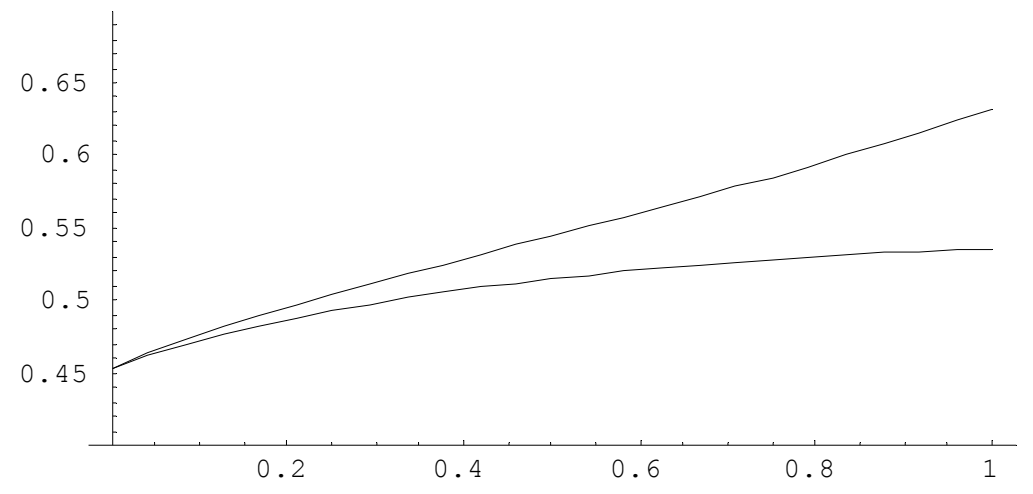

Figure 4: Fig.4: $p_{-1}(\theta, \rho)$ for $\rho=0$ and $\rho=1(\psi=0.6)$.

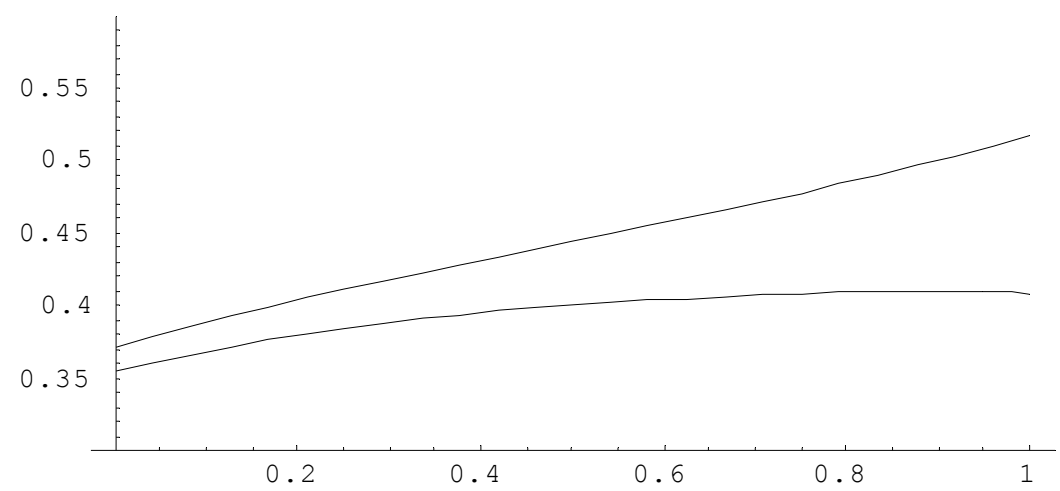

Figure 5: Fig.5: $p_{-1}(\theta, \rho)$ for $\rho=0$ and $\rho=1(\psi=0.4)$. 


\subsection{The effect of technological flows $\delta$}

So far we have assumed that there is perfect patent protection - effectively $\delta=0$. We now wish to briefly consider the impact of imperfect patent protection, namely the case $\delta>0$. Recall that from the discussion in the introduction, patents play no role in neck-and-neck industries and are only relevant in leader-follower industries. Recall also that when patents are imperfect then there is a probability $\delta$ that the follower can simply copy the technology of the leader without acquiring the underlying knowledge behind the technology. Thus if the follower acquires the leader's technology, the industry still remains in a leader-follower situation, all that happens is that the profits of the leader and follower in this situation just become $\pi_{0}$. Thus, the presence of imperfect patents just means that the expected profits of a leader are now $\delta \pi_{0}+(1-\delta) \pi_{1}$ while the expected profits of the follower are now $\delta \pi_{0}+(1-\delta) \pi_{-1}$. Consequently $a=(1-\delta)\left(\pi_{1}-\pi_{0}\right), b=(1-\delta)\left(\pi_{0}-\pi_{-1}\right)$. It is clear therefore that the effect of spillover on innovation and growth can be analyzed in exactly the same way that we analyzed the impact of the level effect on growth in the previous section. We therefore obtain the immediate conclusion:

Theorem 8 An increase in spillover leads to an equi proportionate reduction in $p_{0}, p_{-1}$ and $g$.

Once more, this result is in sharp contrast with those of Aghion et al (1997) who argue that greater ease of imitation can sometimes be growth enhancing. This occurs only in the absence of distinction between the two types of information flows. In our model the two types of information flows have dramatically different impacts on growth. Growth responds positively to increases in $\theta$ but negatively to increases in $\delta$. This is the best justification of the patent system.

\section{Conclusion}

In this paper we have provided a general framework for undertaking a systematic analysis of the impact on innovation and growth of a particular type of increased product market competition - that which comes about through increased rivalry between competitors. In order to develop this framework 


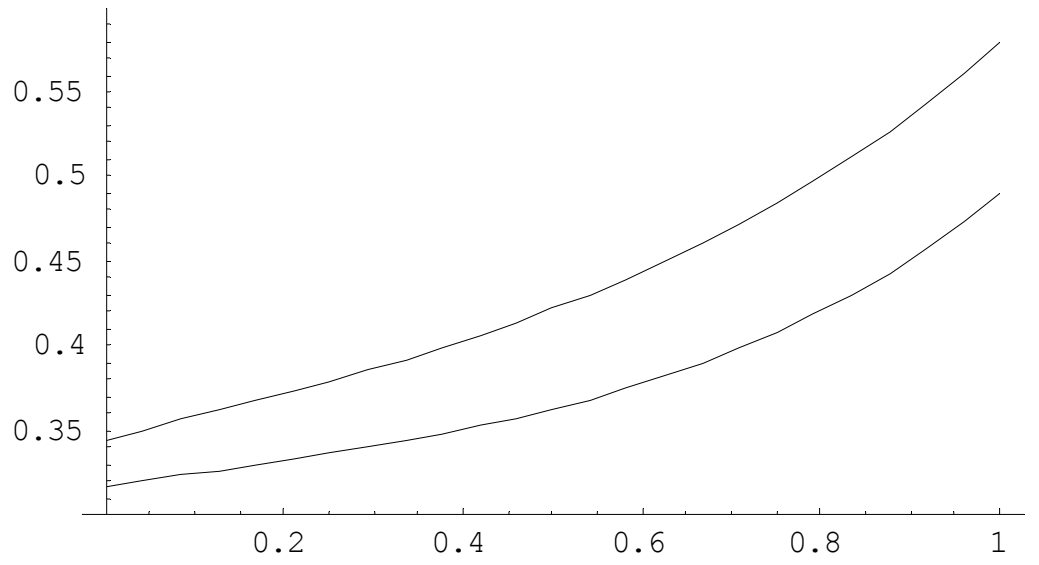

Figure 6: Fig. 6: $g(\theta, \rho)$ for $\rho=0$ (curve below) and $\rho=1(\psi=0.6)$

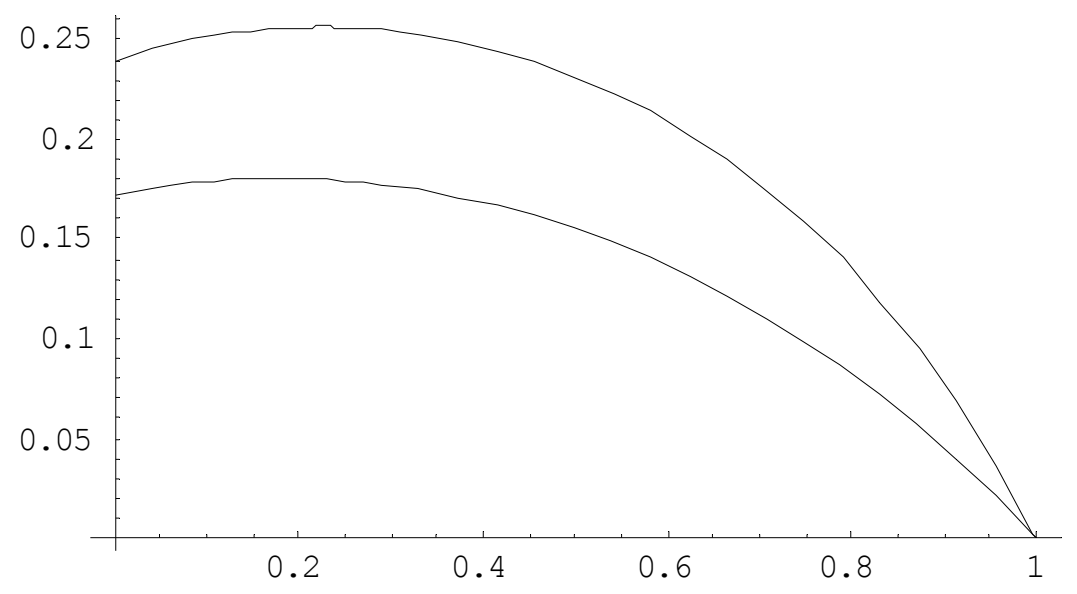

Figure 7: Fig. 7: $\nu(\theta, \rho)$ for $\rho=0$ (curve above) and $\rho=1(\psi=0.6)$. 
we have had to clarify the nature of information flows underpinning the innovation process. In particular we have distinguished flows of information about underlying knowledge - represented by the variable $\theta$ - and flows of information about technology (the conventional spillover parameter) - represented by $\delta$. This general model encompasses both catch-up and what we have called weak leapfrogging (creation without destruction) as special cases where $\theta=0$ and 1 respectively.

We have also argued that the effects of an increase in rivalry can generally be understood as comprising two separate effects - a level effect and a spread effect.

Using this framework we have obtained the following results.

- In the pure catch-up case $(\theta=0)$ an increase in rivalry raises innovation in neck-and-neck industries and increases the R\&D effort of the follower in leader follower industries as long as rivalry is not too intense - specifically as long as $\rho<1-\Psi$. Both of these effects will increase growth. However when rivalry is intense $-\rho>1-\Psi$ - then further increases in rivalry will lower both innovation by the follower and the rate of growth. The threshold from which the competition's effect on growth switches from a positive effect to a negative one in a pure catch-up framework is thus perfectly identified $\left(\rho=1-\Psi=\frac{1}{\varphi}\right)$.

- In the pure leapfrog case $(\theta=1)$ an increase in rivalry always increases both innovation and growth. This result illustrates the importance of the technological diffusion rate in analyzing the effect of competition on innovation and growth.

- In both catch-up and leapgfrog situations the level effect of increased rivalry always reduces innovation and growth while the spread effect increases both innovation and growth.

- In the pure catch-up case an increase in rivalry produces less competitive industries in the sense that the fraction that are neck-and-neck falls. This illustrates the idea that an increase in the short run rivalry lowers the long run competitive structure.

- An increase in $\theta$ raises growth while an increase in $\delta$ lowers it. Insuring simultaneously a higher diffusion rate of the patented knowledge and a better protection of the patented technology constitute thus important policy levers with respect to economic growth based on technological progress.

All these conclusions indicate that the distinctions we have introduced in this paper are worthwhile for understanding the impact of increased compe- 
tition on innovation and growth.

Our model may be improved along different lines. We suggest three possible directions for further research. First, we could increase the number of periods of patent protection. This would allow a richer story of innovation since leaders would now have incentives to increase the gap- and of industrial organization - since industries would comprise more asymmetric firms. Second, the industry dynamics could be enriched by taking into account the fact that innovations may be complementary, in the sense that the overall probability that a successful innovation is reached within a given time increases as each innovator takes a different research line ${ }^{12}$. Third, the technological rate of diffusion is clearly favored by specific individual practices of learning and mastering the knowledge behind the cutting edge technology. These practices are in general costly and the corresponding costs may explain the gap between the states of scientific knowledge and technological development that seems to persist in some countries.

\section{References}

Aghion, P. and P. Howitt (1992), "A model of growth through creative destruction", Econometrica 60, 323-351

Aghion, P. and P. Howitt (1996), "A Schumpeterian perspective on growth and competition", in D. Kreps and K. Wallis, eds. Advances in Economics and Econometrics, Theory and Applications, Cambridge University Press

Aghion, P. and P. Howitt (1998), Endogenous Growth Theory, Mass.: MIT Press

Aghion, P., C. Harris and J. Vickers (1997), "Competition and growth with step-by-step innovation : an example", European Economic Review 41, 771-782

Aghion, P., C. Harris, P. Howitt and J. Vickers (2001), "Competition, imitation and growth with step by step innovation", Review of Economic Studies, 68, 467-492

Anton, and Yao (2004), Little Patents and Small Secrets: Managing Intellectual Property, The Rand Journal of Economics, 35(1),

Arrow, K.J. (1962), "Economic welfare and the allocation of resources for inventions", in R.R. Nelson, ed. The Rate and Direction of Technological

\footnotetext{
${ }^{12}$ See Bessen and Maskin (2002)
} 
Change, Princeton, Princeton University Press

Beath, J., Katsoulacos, Y. and D. Ulph (1987), "Sequential product innovation and industry evolution", Economic Journal, Conference Papers, 97, $32-43$

Bessen, J. and E. Maskin (2002), "Sequential innovations, patents and imitation", W.P., Department of economics, MIT

Boone, J. (2000), "Competitive pressure: the effects on investment in product and process innovation", RAND Journal of Economics, 31(3), 549569

Boone, J. (2001a), "Intensity of competition and the incentive to innovate", International Journal of Industrial Organization, 19(5), 705-726

Boone, J. (2001b), "Competition", mimeo, Tilburg University

Budd, C., C. Harris and J. Vickers (1993), "A model of the evolution of duopoly : does the asymmetry between firms tend to increase or decrease?", Review of Economic Studies 60, 543-573

Caballero, R. and A. Jaffe (1993), "How high are the giants' shoulders? An empirical assessment of knowledge spillovers and creative destruction in a model of economic growth", NBER Macroeconomic Annual, 15-74

Dasgupta, P. and J. Stiglitz (1980), "Uncertainty, industrial structure and the speed of R\&D", Bell Journal of Economics, 11, 1-28

Fudenberg, D. and J. Tirole (1991), Game Theory, Cambridge, Mass.: The MIT Press

Gallini, N. (2002), "The economics of patents: Lessons from recent U.S. patent reform", Journal of Economic Perspectives, 16(2), 131-154

Grossman, G. and E. Helpman (1991), "Quality ladders in the theory of growth", Review of Economic Studies, 58, 43-61

Harris, C. and J. Vickers (1985), "Perfect equilibrium in a model of a race", Review of Economic Studies, 52, 193-209

Harris, C. and J. Vickers (1987)," Racing with uncertainty", Review of Economic Studies, 58, 43-61

Reinganum, J. (1981a), "Dynamic games of innovation", Journal of Economic Theory, 25, 21-41; (1985), "Corrigendum", 35, 196-197

Reinganum, J. (1981b), "On the diffusion of new technology: A game theoretic approach", Review of Economic Studies, 48, 395-405

Reinganum, J. (1981c), "Market structure and the diffusion of new technology", The Bell Journal of Economics, 12, 618-624

Reinganum, J. (1982), "A dynamic game of R\&D: Patent protection and competitive behavior", Econometrica, 50, 671-688 
Reinganum, J. (1985), "Innovation and industry evolution", Quarterly Journal of Economics, 81-99

Reinganum, J. (1989), "The timing of innovation: Research, Development and, Diffusion" in R. Schmalensee and R. Willig eds. The Handbook of Industrial Organization, vol. 1, ch. 14, 849-908

Schumpeter, J. (1934), The Theory of Economic Development, Cambridge, Mass.: Harvard University Press

Vickers, J. (1986), "The evolution of industry structure when there is a sequence of innovations", Journal of Industrial Economics, 35, 1-12 